Results/Outcome Ninety-six homes were included in analysis. Twelve (13\%) had both optimal SA coverage and optimal $\mathrm{H}_{2} \mathrm{O}$ temp. Of the remaining 84, $23(27 \%)$ either acquired a SA or lowered $\mathrm{H}_{2} \mathrm{O}$ temp by $>5^{\circ}$ on follow-up assessment. Of those who still lacked optimal SA or $\mathrm{H}_{2} \mathrm{O}$ temp, 38 (62\%) reported trying to make one of the changes. Participants reported that the most important factor for making a change was having an individual check the $\mathrm{SA}$ and $\mathrm{H}_{2} \mathrm{O}$ temp.

Significance/Contribution to the Field Using non-professional educators to incorporate injury prevention messages into an existing home visitation programme may be an effective way to increase working SA prevalence and improving $\mathrm{H}_{2} \mathrm{O}$ temp, especially if it includes physically checking the status of SAs and $\mathrm{H}_{2} \mathrm{O}$ temp.

\section{2 CAN LAY EDUCATORS BE USED TO INTEGRATE INJURY PREVENTION MESSAGES INTO HOME VISITATION PROGRAMMES?}

\author{
doi:10.1136/injuryprev-2012-040590a.2
}

${ }^{1} \mathrm{~S}$ Stephens-Stidham, ${ }^{1} \mathrm{I}$ Colunga, ${ }^{2} \mathrm{C}$ Mowell, ${ }^{3} \mathrm{U}$ Johnson, ${ }^{1} \mathrm{G}$ Istre. ${ }^{1}$ Injury Prevention Center of Greater Dallas, USA; ${ }^{2}$ University of North Texas, USA; ${ }^{3}$ University of Texas Medical School, USA

Background Home visitation programmes by professionals have been proven effective at reducing certain injuries, yet there are limited data about the efficacy of the use of non-professionals in these programmes. The Injury Prevention Center (IPC) partnered with an established education-oriented home visitation programme, to include burn prevention messages, and evaluated its impact on two measurable prevention behaviors: smoke alarm (SA) prevalence and hot water temperature $\left(\mathrm{H}_{2} \mathrm{O}\right.$ temp).

Aims/Objectives/Purpose To measure the impact of the intervention on working SA prevalence and $\mathrm{H}_{2} \mathrm{O}$ temp in Irving, TX.

Methods Home visitors provided literature and verbal educational messages about the importance of SAs and appropriate $\mathrm{H}_{2} \mathrm{O}$ temp (ie, $<120 \mathrm{~F}$ ) to parents. Trained IPC staff assessed working SA status and tap $\mathrm{H}_{2} \mathrm{O}$ temp in each intervention home initially and 2 months later. 